\title{
Structure-Property Relations in Polymer:Fullerene Blends for Organic Solar Cells
}

\author{
Natalie Banerji* \\ SCS Grammaticakis-Neumann Prize 2015
}

\begin{abstract}
Organic solar cells consist of thin films combining an electron donor (often a conjugated polymer) with an electron acceptor (often a fullerene derivative), in a blend commonly referred to as bulk heterojunction material. Charge separation between the donor and the acceptor leads to the generation of carriers, which can be extracted from photovoltaic devices in the form of photocurrent. The generation mechanism of free, extractable charges has caused a lot of controversial discussion in literature. Our research has shown that all the steps involved in charge generation are strongly dependent on the arrangement of the donor and the acceptor (i.e. the structure) of the bulk heterojunction.
\end{abstract}

Keywords: Charge generation $\cdot$ Charge transport $\cdot$ Microstructure $\cdot$ Organic solar cells $\cdot$ Ultrafast spectroscopy

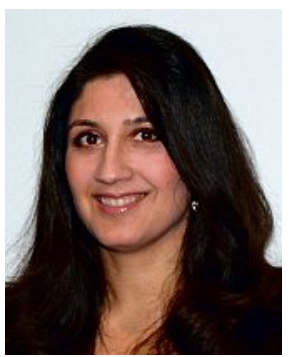

Natalie Banerji was born and raised in Geneva (Switzerland), although she is originally Austrian. She studied Chemistry at the University of Geneva and obtained her Ph.D. in Physical Chemistry in 2009, under the supervision of Prof. Eric Vauthey. She then moved to the University of California in Santa Barbara (USA), to work on organic solar cells during a post-doctoral stay with Prof. Alan J. Heeger (2009-2011). In 2011, she was given the opportunity to start her independent research career in Switzerland at the Ecole Polytechnique Férérale de Lausanne (EPFL) with an Ambizione Fellowship by the Swiss National Science Foundation (SNSF). She obtained an SNSF-Professorship at the University of Fribourg (Switzerland) in 2014, and was subsequently nominated tenured Associate Professor in 2015.

${ }^{\star}$ Correspondence: Prof. Dr. N. Banerj Department of Chemistry

University of Fribourg

Chemin du Musée 9, CH-1700 Fribourg

E-mail: natalie.banerji@unifr.ch

\section{Introduction}

In the 1980s, the first organic photovoltaic (OPV) device having an interface between an electron donor layer and an electron acceptor layer was reported. ${ }^{[1]}$ The junction is necessary in order to efficiently dissociate bound excitons in organic solids, unlike for inorganic materials, where free charges can be directly generated by light absorption. Another breakthrough in the field was the demonstration of the bulk heterojunction (BHJ) in 1995. [2] This implies blending the donor and acceptor materials to form a nanoscale interpenetrating network, allowing on the one hand a large interfacial area for exciton dissociation, and on the other hand a percolating network for charge transport to the electrodes. Today, the efficiency in OPV devices exceeds $11 \% .{ }^{[3]}$ The main advantage of this technology is the low-cost manufacturing of solution-processed devices, which are large-area, flexible and lightweight.

The most commonly used materials in organic solar cells are $\pi$-conjugated polymer electron donors, blended with electron-accepting fullerene derivatives such as PCBM $\left([6,6]\right.$-phenyl- $\mathrm{C}_{61}$-butyric-acidmethyl-ester). They can be dissolved in a common organic solvent, and then cast or printed to highly absorbing thin films of about $100 \mathrm{~nm}$ thickness. An over-simplified picture of the processes occurring in this BHJ blend is shown in Fig. 1a. This includes: 1) light absorption by the polymer, 2) diffusion of the generated exciton to an interface with PCBM, 3) exciton dissociation to a bound electron-hole pair,

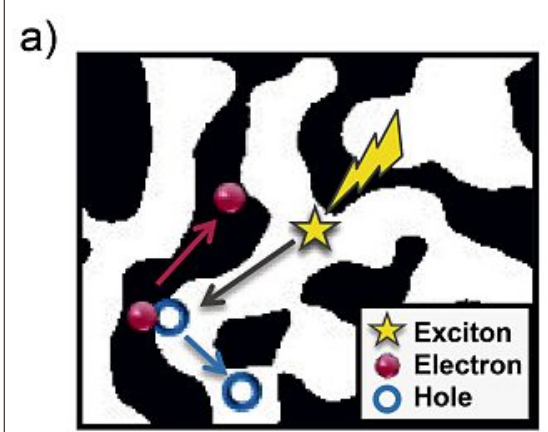

b)

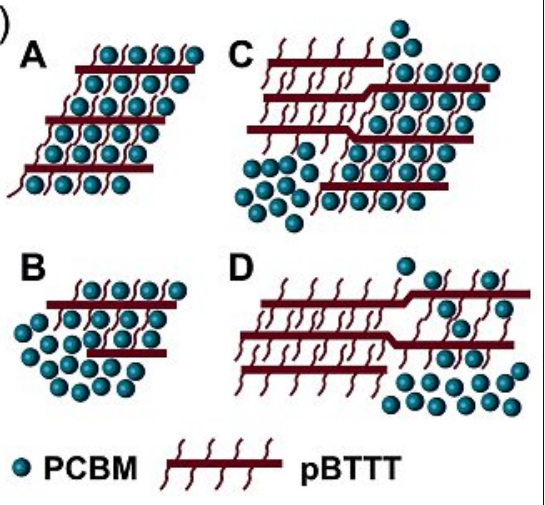

Fig. 1. a) Highly simplified picture of the processes occurring in a polymer:fullerne blend upon photo-excitation: 1) Light absorption by the polymer (white), 2) diffusion of the exciton to an interface with PCBM (black), 3) exciton dissociation to a bound electron-hole pair, and 4) separation into free charges that are extracted at the electrodes. b) Schematic representation of the investigated phase morphologies of pBTTT:PCBM blends: Fully intermixed (A), co-crystal regions co-existing with neat PCBM clusters (B), partially phase-separated (C), and predominantly phase-separated (D). 
and 4) separation into free charges that are extracted at the electrodes. ${ }^{[4]}$ The detailed mechanisms of exciton dissociation, charge pair separation and carrier transport are highly complex and have created several controversial views in the OPV community. We review here aspects of our research, which have revealed that the microstructure and phase morphology of the $\mathrm{BHJ}$, i.e. the precise arrangement of the donor and the acceptor from the molecular to microscopic scale, play a determining role in these processes.

\section{The pBTTT:PCBM Model System}

In the OPV field, many empirical ways to enhance solar cell efficiency by influencing the BHJ structure during solutionprocessing of the thin films have been developed (e.g. casting solvent optimization, use of additives, thermal/solvent annealing). [5] With recent advances in structural characterization of organic thin films, ${ }^{[6]}$ it has become clear that the simple two-phase picture shown in Fig. 1a is not pertinent. Not only can the polymer and fullerene components arrange into either amorphous or crystalline neat domains of variable size, but an additional intermixed polymer:fullerene phase has been identified. [7] The three-phase morphology, consisting of co-existing intermixed polymer:fullerene regions with neat polymer and fullerene domains, leads to highest OPV efficiency. ${ }^{[8]}$

In order to correlate the charge generation and transport properties in polymer:fullerene blends to the structure of the BHJ films, we have worked with a model system where the phase morphology can be precisely characterized and controlled: The blend of the pBTTT polymer (poly(2,5-bis(3-hexadecyl-thiophen-2-yl) thieno[3,2-b]thiophene) with PCBM. [8b,d,9] This polymer is known for a highly ordered microstructure and for excellent performance in field effect transistors. ${ }^{[10]}$ It has been shown that fullerene molecules intercalate between the side chains of the ordered pBTTT domains, forming a well-defined intimately mixed cocrystal phase. ${ }^{[\mathrm{b}, \mathrm{d}]}$ Moreover, the phase morphology of the pBTTT:PCBM blends can be manipulated, either by changing the polymer:fullerene weight ratio, or by using fatty acid methyl ester additives of different alkyl chain lengths (Me 7, Me 12 and Me 14). ${ }^{[8 b, 9]}$ The four phase morphologies that we investigated are shown in Fig. 1b: Fully intermixed (A, 1:1 pBTTT: PCBM weight ratio), intermixed co-crystal regions and neat PCBM clusters $(\mathbf{B}, 1: 4$ weight ratio), partially intercalated $(\mathbf{C}, 1: 1$ weight ratio processed with $\mathrm{Me} 7$ ), and pre- dominantly phase-separated (D) 1:1 weight ratio processed with Me 12 or Me 14).

\section{Effects of the Phase Morphology on the Photophysics}

\subsection{Absorption Spectra}

The absorption spectra of neat pBTTT films (without PCBM) and of the pBTTT:PCBM blends with the four investigated phase morphologies are shown in Fig. 2. ${ }^{[11]}$ Neat pBTTT films processed at room temperature have a featureless absorption band peaking at $525 \mathrm{~nm}$, and they emit around $700 \mathrm{~nm} .{ }^{[12]}$ For fully intercalated pBTTT:PCBM samples (phase morphology A), the absorption of the polymer in the co-crystal phase becomes structured and more red-shifted (maximum around $560 \mathrm{~nm}$ ). This is likely related to the different conformation and packing of the pBTTT chains in the co-crystal phase compared to the neat phase. ${ }^{[13]}$ It has also been shown that the valence band of pBTTT shifts by up to $320 \mathrm{meV}$ upon fullerene intercalation, which is related to intermolecular interactions. ${ }^{[14]}$ An interfacial charge transfer (CT) state between pBTTT and PCBM can be directly excited from the ground state, and leads to a weak absorption band in the 750-1200 nm region, as seen by sensitive photothermal deflection spectroscopy (PDS). ${ }^{[15]}$

In the samples with phase morphology $\mathbf{B}$ (co-existing intermixed phase with neat PCBM clusters), the absorption of PCBM below $450 \mathrm{~nm}$ is strongly enhanced due to the higher fullerene content, while the structured shape of the pBTTT band around $560 \mathrm{~nm}$ confirms that the polymer is present in the co-crystal phase (Fig. 2). Because of fullerene crystallization in the neat PCBM clusters, the electron affinity increases by $100-200 \mathrm{meV}$ with respect to PCBM in the co-crystal domains. ${ }^{[8 b]}$
When the pBTTT:PCBM blends are partially or predominantly phase-separated using the processing additives (phase morphologies $\mathbf{C}$ and $\mathbf{D}$ ), the removal of PCBM from the co-crystal regions leads to the presence of neat pBTTT domains, as clearly reflected by the shape of the polymer absorption in the $500-600 \mathrm{~nm}$ region (Fig. 2). This is a superposition of the featureless blue-shifted contribution of pBTTT in the neat domains, and the structured red-shifted contribution of pBTTT remaining in co-crystal regions. The phaseseparation in those samples has been confirmed by a variety of tools (grazing-angle incidence wide-angle X-ray scattering, scanning transmission X-ray microscopy, optical microscopy, resonant soft X-ray scattering). ${ }^{[9]}$ It has also been shown by PDS spectroscopy, that the intensity of direct CT-state absorption is reduced in the phase-separated blends, due to a decrease in the polymer:fullerene interfacial area. ${ }^{[15 b]}$ Finally, there is a noticeable reduction in the relative absorption of PCBM below $450 \mathrm{~nm}$ in the predominantly phaseseparated blends (Fig. 2, phase morphology D), although they contain the same amount of fullerene as the fully intercalated samples with phase morphology A. This is possibly related to enhanced long-range ordering in the neat PCBM regions. ${ }^{[16]}$

\subsection{Exciton Dissociation}

Exciton dissociation to charges in polymer:fullerene blends has been shown to occur on the ultrafast time scale, in less than $100 \mathrm{fs} .{ }^{[17]}$ This has raised considerable questions, since such a fast time scale is not consistent with exciton diffusion through neat polymer domains over a distance of about $10 \mathrm{~nm}$, in order to reach a PCBM quenching site, as suggested by Fig. 1a. One hypothesis that we and others suggested, is that excitons are highly delocalized for about 100-200 fs after photo-ex-

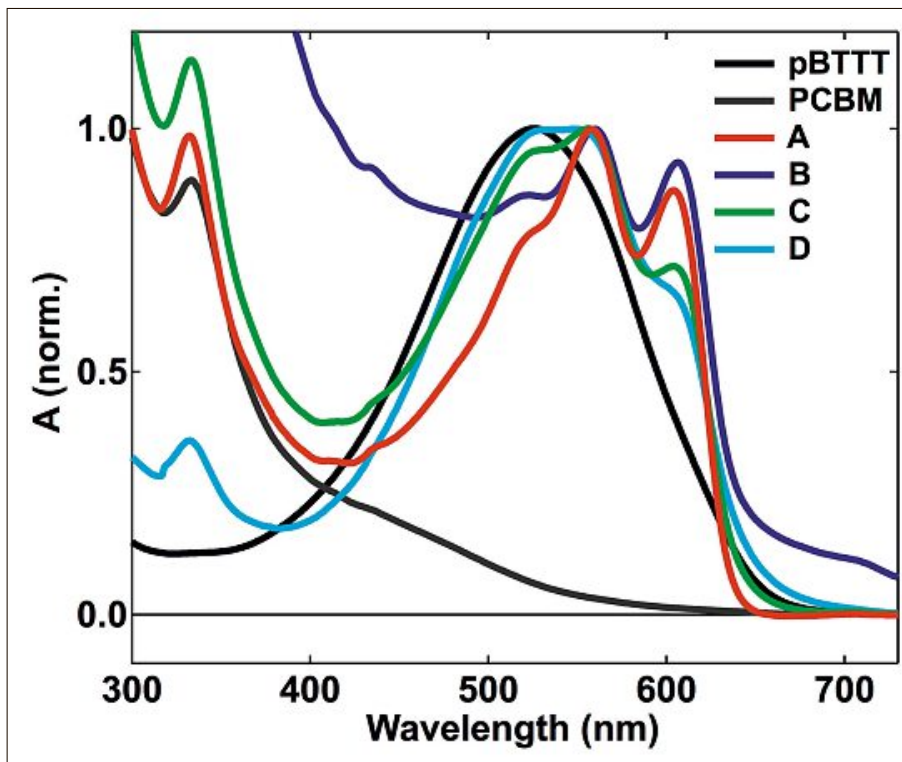

Fig. 2. Absorption spectra of neat PBTTT films, neat PCBM films and pBTTT:PCBM blends with different phase morphologies: Fully intermixed (A), co-crystal regions co-existing with neat PCBM clusters (B), partially phaseseparated (C), and predominantly phaseseparated (D). 
citation, so that they sample a larger extent of the BHJ, and that their dissociation takes place before excited-state relaxation to a more localized species. ${ }^{[18]}$ Subsequently, we have shown that an even more important parameter leading to ultrafast exciton dissociation in polymer:fullerene blends is the presence of the intermixed phase. ${ }^{[11,19]}$ We found that prompt ( 100 fs) exciton dissociation occurs predominantly in the regions where the polymer and fullerene are molecularly intermixed, so that no exciton diffusion is necessary. On the other hand, slower (delayed) exciton dissociation is observed, if the excitons need to diffuse through neat domains to a quenching site.

For fully intercalated pBTTT:PCBM blends (phase morphology A), $>99 \%$ of the polymer emission is quenched due to efficient electron transfer (ET) to PCBM in the intermixed co-crystal phase. ${ }^{[8 \mathrm{~b}]} \mathrm{We}$ have shown by time-resolved fluorescence spectroscopy that this occurs with a $\sim 100 \mathrm{fs}$ time constant (inset of Fig. 3). ${ }^{[1]}$ We also measured femtosecond transient absorption (TA) spectra of the samples.[11,19a,b] This allows to observe the dissociation of the excitons as well as the rise of signatures related to the photo-generated charges. Due to the prompt exciton dissociation in the fully intercalated blend, the typical exciton-state absorption (ESA) above 800 $\mathrm{nm}$ is not seen, even at the earliest measurable time delay $(0.2 \mathrm{ps})$. Instead, the signature due to charges is instantaneously present (Fig. 3a,b).

We have revealed similarly prompt quenching by ET when exciting the pBTTT polymer present in the co-crystal regions of samples with phase morphology $\mathbf{B}$ (co-existing intermixed phase with neat PCBM clusters). However, when selectively exciting the PCBM, both prompt and delayed charge generation dynamics are observed. ${ }^{[8 b, 11,12,19 a, b]}$ In this case, excitons are photo-generated in the fullerenes and dissociate by hole transfer (HT) to pBTTT. Since PCBM is present both in the co-crystal regions and the neat fullerene clusters, part of the excitons need to diffuse over various distances through the neat PCBM domains prior to their dissociation, leading to strongly multiphasic quenching dynamics with time constants ranging from sub-picosecond to hundreds of picoseconds. It is likely that some of the excitons never reach a quenching site during their lifetime, especially if the fullerene domains are larger than the $5 \mathrm{~nm}$ exciton diffusion length of PCBM. ${ }^{[20]}$ In the corresponding TA spectra, the weak signature of the PCBM excitons is hidden by the other spectral features (Fig. 3c). However, the delayed HT is clearly evident as a progressive rise of the negative ground-sate bleaching (GSB) signature of pBTTT, since the poly-

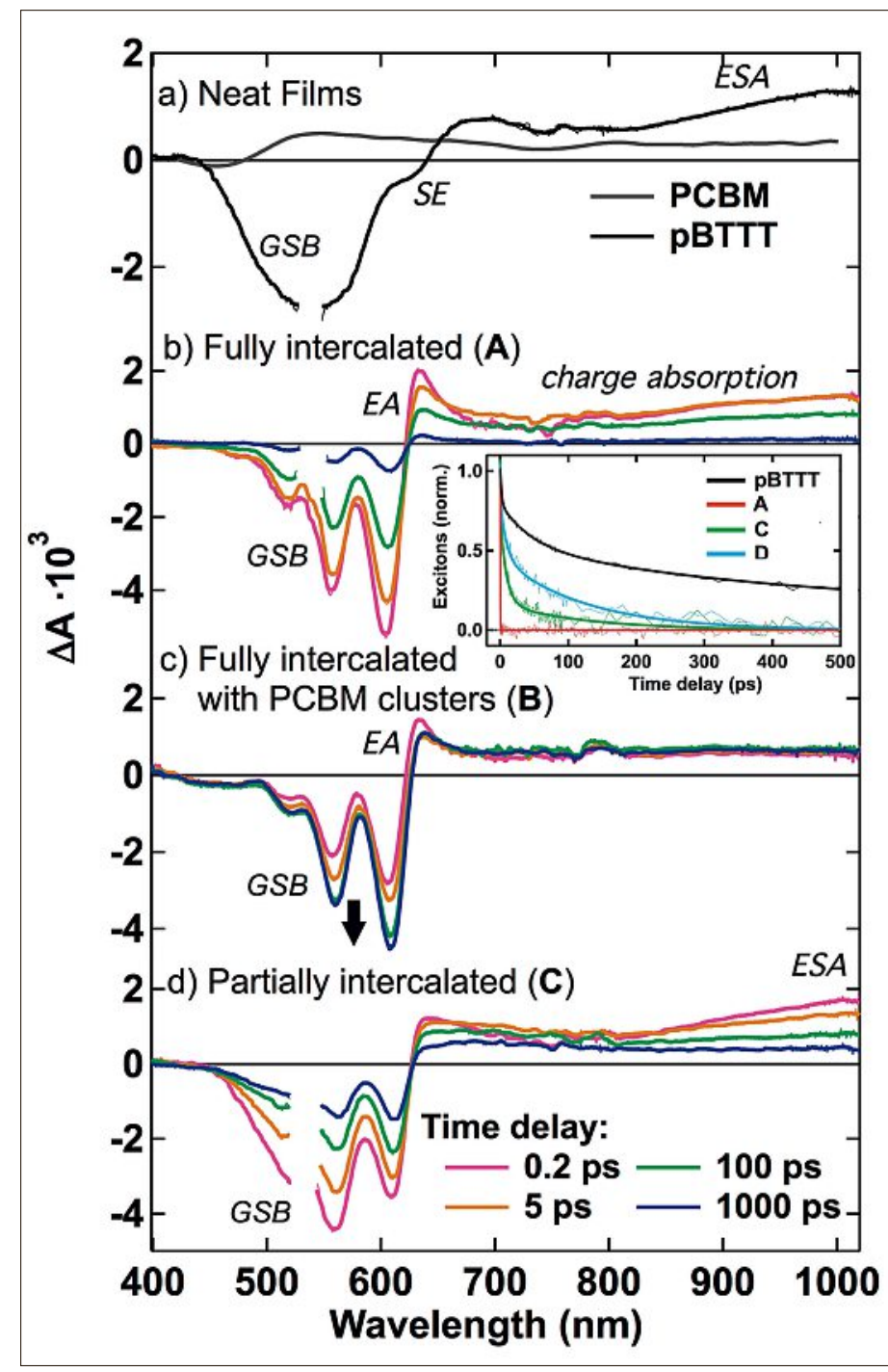

Fig. 3. Transient absorption (TA) spectra of a) neat PBTTT and neat $P C B M$ films, and b)-d) of pBTTT:PCBM blends with different phase morphologies, at various time delay after photoexcitation. In b) and d), the polymer was selectively excited, while the PCBM was selectively excited in c). Typical signatures include the ground state bleaching (GSB), stimulated emission (SE), excited-state absorption (ESA), charge absorption, and electroabsorption (EA).

The inset shows the dynamics of pBTTT excitons (obtained either by time-resolved emission spectroscopy, or by analysis of the TA data). Data from ref. [11]. mer states are not directly excited, but indirectly populated via the HT process.

Neat pBTTT domains are present in the phase-separated pBTTT:PCBM blends (phase morphologies $\mathbf{C}$ and $\mathbf{D}$ ). As expected, this decreases the quenching efficiency of the pBTTT excitons (the polymer emission is about $75 \%$ quenched in predominantly phase-separated blends, instead of $<99 \%$ in the fully intercalated samples). [9] In the TA spectra with selective polymer excitation, the absorption signature of the pBTTT excitons above $800 \mathrm{~nm}$ is clearly visible at early time delays for the phaseseparated samples (Fig. 3d). ${ }^{[11,19 a]}$ The signature of those pBTTT excitons decays faster for the partially than for the predominantly phase-separated blends, and in both cases faster than for neat pBTTT films (inset of Fig. 3). We attribute the multiphasic quenching in the phase-separated blends, with time constants of 0.6 ps, 9 ps and 125 ps, to delayed ET after exciton diffusion though the neat pBTTT domains towards PCBM. About 10-20\% of the excitons generated within the neat polymer domains are lost to the ground state and never dissociate during their lifetime. ${ }^{[19 a]}$

\subsection{Free Charge Generation versus Recombination}

Once that the excitons have dissociated at a polymer:fullerene domain-interface or molecular boundary in the intermixed regions, the generated electron-hole pairs can either spatially separate to free charges, or geminately recombine to the ground state. The detailed mechanism of free charge generation in organic solar cells is still highly debated, with conflicting accounts of ultrafast free charge generation, ${ }^{[21]}$ and of slowly separating CT-states. ${ }^{[22]}$ Ultrafast free charge generation has been justified by long-range charge separation, ${ }^{[21 \mathrm{a}, \mathrm{c}, \mathrm{d}]}$ by delocalization into neat domains, ${ }^{[21 b]}$ and by the contribution of hot states. ${ }^{[21 e]}$ On the other hand, the dissociation of relaxed CT-states has been related to high local charge carrier mobility. ${ }^{[22 a]}$ Our results with the pBTTT:PCBM blends reconcile the contradictory hypotheses reported in literature. ${ }^{[19 a]}$ We have shown that whether the electron-hole pairs are able to dissociate or not is instantaneously determined at the moment of their generation (by the molecular arrangement and local environment of the charge pairs, which mainly affect their electronic coupling). However, 
the spatial dissociation of the charges to reach the $\sim 5 \mathrm{~nm}$ electron-hole separation needed to overcome their Coulomb attraction is relatively slow, and can take 5-30 ps depending on the phase morphology.

In Fig. 3, it is clear that the lifetime of the TA signatures representing the charges is strongly dependent on the phase morphology. The dynamics of the charges (upon selective excitation of the polymer) was extracted and is shown in Fig. 4a. ${ }^{[19 a]}$ There is a partial decay of the charge dynamics with a time constant of about 200 ps due to geminate charge recombination ( $\mathrm{gCR}$ ), concerning predominantly the charge pairs that were promptly generated in the cocrystal phase. The amplitude of this gCR decreases from $87 \%$ (fully intercalated blend, phase morphology A), to $72 \%$ (predominantly phase-separated blend, phase morphology D), to $49 \%$ (partially phaseseparated blend, phase morphology $\mathbf{C}$ ), and to $30 \%$ (co-existing intermixed phase with neat PCBM clusters, phase morphology B). The trend correlates inversely with the solar cell efficiency of the corresponding photovoltaic devices. ${ }^{[9,23]}$ This shows that $\mathrm{gCR}$ is a loss mechanism strongly reducing solar cell efficiency, but which can be prevented by the presence of neat PCBM clusters and/or neat pBTTT domains. The extent of gCR also scales with the amplitude of direct CT-state absorption, ${ }^{[15]}$ confirming that the recombination occurs from interfacial electron-hole pairs.

In agreement with the fact that neat domains reduce $\mathrm{gCR}$, TA measurements on the longer (microsecond) time scale indicate a higher yield of long-lived free charges (polarons) in the pBTTT:PCBM samples having neat PCBM domains and in the phase-separated blends (phase morphologies $\mathbf{B}, \mathbf{C}$ and $\mathbf{D})$, compared to the fully intercalated blends (phase morphology A). ${ }^{[8 b, 9]}$ It was also found that the nature of the long-lived pBTTT polarons is more localized in the intermixed phase, while it is more delocalized in neat pBTTT domains. ${ }^{[24]}$ Finally, it was reported that slow recombination processes are trap-based in fully intercalated samples, while they are bimolecular in blends containing neat PCBM clusters. ${ }^{[25]}$

The beneficial impact of neat phases on the spatial separation of electronhole pairs for pBTTT:PCBM blends and polymer:fullerene blends in general has been known for some time, and explains why best solar cell efficiency is usually obtained in three-phase morphologies combining intermixes regions with neat polymer and fullerene domains. ${ }^{[8,22 a, 26]}$ Different mechanisms for this phenomenon have been invoked, such as improved transport in the neat regions, ${ }^{[22 a, 23]}$ electron delocalization into the fullerene clusters $^{[21 b, 27]}$ or energy cascades driving

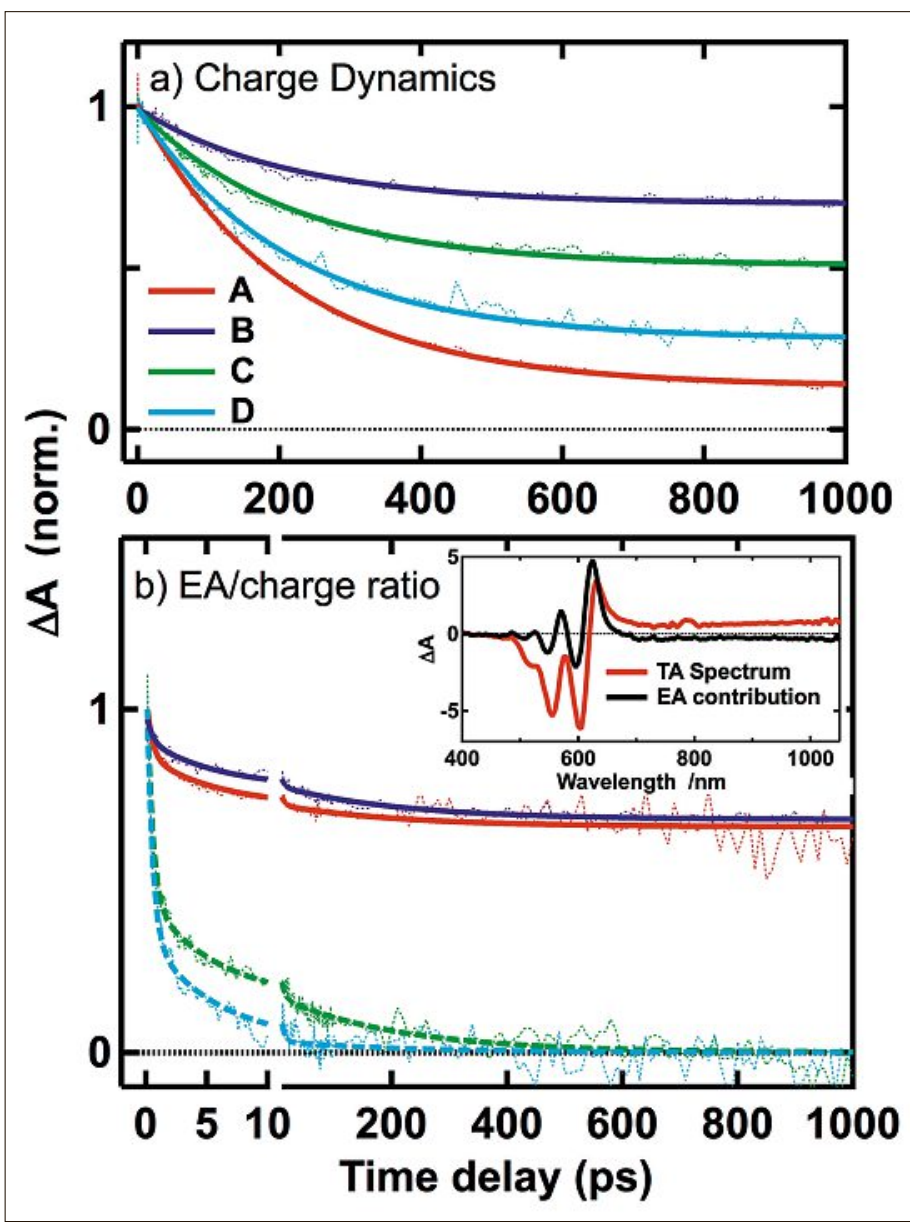

Fig. 4. Normalized dynamics of a) the charge carriers and b) the electro-absorption (EA) contribution scaled by the dynamics of the charges, obtained from the analysis of the TA data in PBTTT:PCBM blends with different phase morphologies: Fully intermixed (A), co-crystal regions co-existing with neat PCBM clusters (B), partially phase-separated (C), and predominantly phase-separated (D). The inset shows a typical EA spectrum extracted from the TA spectrum of the fully intercalated blend. Data from refs [11] and [19a].

the charges from the intermixed to the neat regions. ${ }^{[8 b, 14,22 a]}$

It is difficult to learn about the spatial separation of charges using TA spectroscopy, since electron-hole pairs and free charges typically have very similar spectral signatures. However, we were able to identify a contribution of electroabsorption (EA) in the TA spectra of the pBTTT:PCBM blends (inset of Fig. 4b). This is caused by the local electric field that exists around photo-generated charges, leading to a Stark shift in the absorption of the chromophores found in their immediate vicinity. ${ }^{[19 a, 21 b]}$ We could assign the observed EA signal to transitions in the pBTTT polymer, and more specifically to the presence of holes in the co-crystal phase. ${ }^{[11,19 a]}$ We found that the EA due to holes in the neat pBTTT domains and due to electrons in PCBM is negligible in the TA measurements. Therefore, the presence of the EA signature is a direct probe of whether holes are found in the co-crystal regions or neat PBTTT domains. Fig. 4b shows the temporal evolution of the EA signature for different phase morphologies (scaled by the dynamics of the charges). For fully intercalated blends and blend containing co-crystal regions and PCBM clusters (phase morphologies $\mathbf{A}$ and $\mathbf{B}$, polymer excitation), the EA contribution stays constant after some initial relaxation, since the charges do not have the possibility to migrate to any neat pBTTT domains. On the other hand, over $85 \%$ of the EA contribution disappears within a few picoseconds (mainly in $<1 \mathrm{ps}$ ) in the phaseseparated blends (phase morphologies $\mathbf{C}$ and $\mathbf{D}$, selective co-crystal excitation), and the TA spectra at long times do not show any EA (Fig. 3d). This indicates ultrafast transport of the holes generated in the cocrystal regions to neat pBTTT domains.

Moreover, we have used electromodulated differential absorption (EDA) spectroscopy in order to directly visualize the separation of the electron-hole pairs as a function of phase morphology. In this technique, an external reverse bias (yielding a homogeneous electric field of the order of $105 \mathrm{~V} \cdot \mathrm{cm}^{-1}$ ) is applied across full solar cells containing the pBTTT:PCBM films, thus externally inducing a bulk EA response in the active layer (Fig. 5a). ${ }^{[19 a]}$ When the devices are photo-excited, the transport and extraction of the photo-generated charges shields the external reverse bias and reduces the amplitude of the EA signal. The voltage-drop in the solar cells due to this evolution of the charges can be deduced with femtosecond resolution. EDA spectroscopy is sensitive only to those electronhole pairs, which dissociate to free charges and are transported to the electrodes (in contrast to TA measurements, where both 
bound and free charges are seen). Indeed, the magnitude of the voltage drop obtained by the EDA technique scales with the yield of free charge generation in a given phase morphology (Fig. 5b). Thus, we observed a voltage drop on the $1 \mathrm{~ns}$ time scale of $\sim-0.3 \mathrm{~V}$ in the fully intercalated blend (phase morphology $\mathbf{A}$ ), which increased to $\sim-2.8 \mathrm{~V}$ in the blend containing additional PCBM clusters (phase morphology B), where $\mathrm{gCR}$ is reduced and free charge generation is favoured (measurements were carried out at $-6 \mathrm{~V}$ applied bias and similar excitation densities).

From the voltage drop dynamics, we have calculated the time-resolved average electron-hole separation (sum of the electron and hole motions in the direction towards the electrodes, Fig. 5c). ${ }^{[19 a]}$ In the fully intercalated blends and the ones with additional PCBM clusters (phase morphologies $\mathbf{A}$ and $\mathbf{B}$, with polymer excitation), the charges initially evolve only in the co-crystal phase, leading in both cases to a charge separation by about $3 \mathrm{~nm}$ within 10 ps. After 10 ps, the electron-hole distance is strongly increased only for phase morphology $\mathbf{B}$ (containing the additional fullerene clusters), compared to phase morphology A (containing just the cocrystal phase). This shows that after $10 \mathrm{ps,}$ the electrons have reached the neat PCBM regions, where the electron transport is improved. ${ }^{[12,28]}$ For the predominantly phaseseparated blend (phase morphology $\mathbf{D}$, with selective co-crystal excitation), there is an ultrafast electron-hole separation of $\sim 2 \mathrm{~nm}$ in only $200 \mathrm{fs}$. As discussed above, we attribute this to holes travelling from the co-crystal regions to neat pBTTT domains (probably within the same polymer chain and helped by initial delocalization).

Comparing the voltage drop dynamics of phase morphologies $\mathbf{A}$ and $\mathbf{B}$ (Fig. $5 \mathrm{~b}$ ), the drop within the first picosecond is more pronounced in the presence of neat fullerene clusters. This indicates that the number of dissociating electron-hole pairs is increased in phase morphology $\mathbf{B}$ from the earliest time onwards, although the average electron-hole separation only differs after $10 \mathrm{ps}$, once the electrons have reached the neat PCBM regions. From this, together with bias-dependent measurements, we have concluded that the branching between electron-hole pairs that will undergo gCR and those that will be able to separate to free charges is determined instantaneously, at the moment of their generation by exciton dissociation. ${ }^{[19 a]}$ Nearby neat phase domains can shift the branching ratio towards more free charge generation.

Nevertheless, even if the ability of charge pairs to dissociate is determined on the sub-100 fs time scale, the spatial dissociation of the charges to reach the $\sim 5 \mathrm{~nm}$ electron-hole separation needed to overcome their Coulomb attraction is relatively slow, and can take 5-30 ps depending on the phase morphology (Fig. 5c). This is because the transport is very dispersive in all the blends (slows down with increasing distance as charges become increasingly trapped). ${ }^{[29]}$ In spite of revealing high local mobility and positive impact of certain phase morphologies on the transport, our results therefore also agree with previously reported slow dissociation to free charges. ${ }^{[22]}$

\section{Conclusion}

By using a complementary palette of femtosecond-resolved spectroscopic experiments, including Stark effect spectroscopies in the absence and presence of externally applied electric fields, we have clearly established how the phase morphology of polymer:fullerene blends affects the different steps involved in pho- ton-to-current conversion, exciton dissociation, free charge generation and charge transport. Our studies were focussed on the pBTTT:PCBM model system, where the phase morphology can be precisely controlled and characterized. Nevertheless, our conclusions are generally relevant and important, because the interplay of neat and intermixed phases in donor:acceptor blends has been identified as a key factor for optimized solar cell efficiency. We are currently investigating other more amorphous polymer:fullerene blends with high solar cell efficiency and find similar results.

\section{Acknowledgements}

I thank the Swiss Chemical Society for having awarded me the Grammaticakis-Neumann Prize in 2015. This success would not have been possible without the hard work of the involved students and postdocs: Thank you Dr. Jan Brauer, Martina Causa', Lisa Peterhans, Nikos Droseros, Dr. Demetra Tsokkou, Dr. Mariateresa Scarongella, Dr. Jelissa De Jonghe-Risse, and Arun Paraecattil. I would also like to thank the many scientists I am collaborating with, especially those from Imperial College London, who closely worked with me on the projects presented in this review article: Dr. Ester Buchaca-Domingo, Prof. Natalie Stingelin and Prof. Martin Heeney. Many thanks go also to Prof. Eric Vauthey, Prof. Alan J. Heeger and Prof. Jacques Moser for their advice, help and support and for having hosted me in their laboratories at different stages of my career. Finally, I would like to acknowledge the financial support from the Swiss National Science Foundation and the University of Fribourg.

Received: April 26, 2016

[1] C. W. Tang, Appl. Phys. Lett. 1986, 48, 183.

[2] a) G. Yu, J. Gao, J. C. Hummelen, F. Wudl, A. J. Heeger, Science 1995, 270, 1789; b) J. J. M. Halls, C. A. Walsh, N. C. Greenham, E. A.

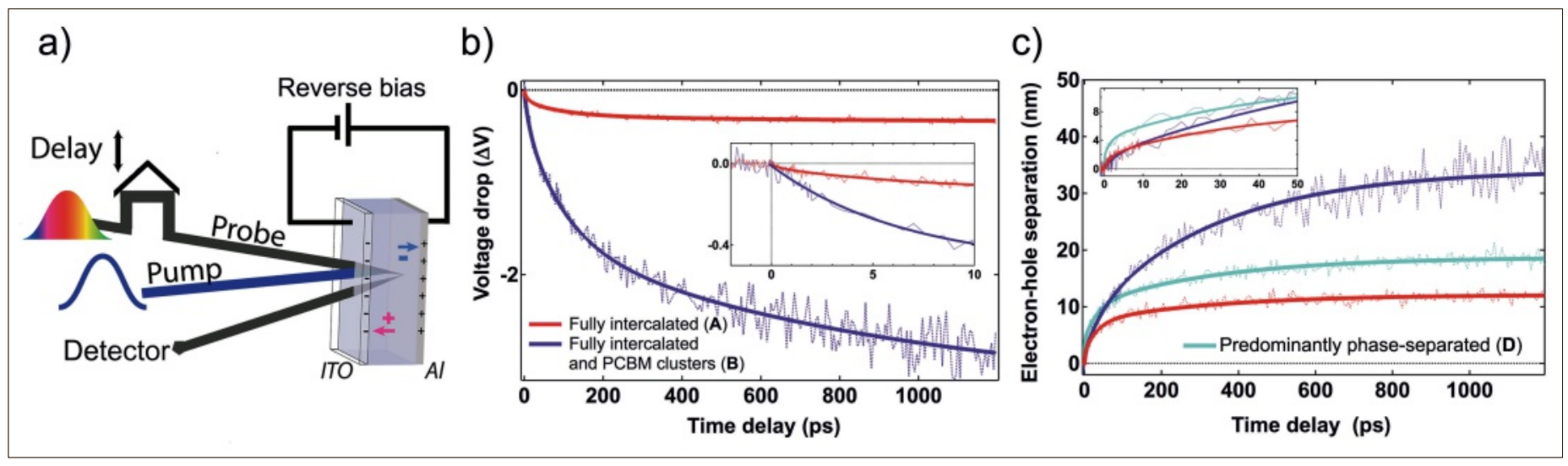

Fig. 5. a) Schematic representation of the setup used for time-resolved electromodulated differential absorption (EDA) spectroscopy on full solar cell devices under reverse bias. b) Voltage drop $(\Delta \mathrm{V})$ dynamics obtained from the EDA decay for the investigated pBTTT:PCBM devices, at reverse biases of $-6 \mathrm{~V}$, upon excitation of the polymer at a fluence of $\sim 1.0 \mu \mathrm{J} / \mathrm{cm}^{2}$. c) Average electron-hole separation calculated from the voltage drop across the devices at $-6 \mathrm{~V}$. The insets zoom on the early time delays. Data is shown for fully intermixed blends (A, red), samples having co-crystal regions co-existing with neat PCBM clusters (B, violet), and predominantly phase-separated blends (D, cyan, with selective co-crystal excitation). Data from ref. [19a]. 
Marseglia, R. H. Friend, S. C. Moratti, A. B Holmes, Nature 1995, 376, 498.

[3] M. A. Green, K. Emery, Y. Hishikawa, W. Warta, E. D. Dunlop, Prog. Photovolt: Res. Appl. 2015 , 23,805 .

[4] B. C. Thompson, J. M. J. Fréchet, Angew. Chem., Int. Ed. 2008, 47, 58.

[5] a) J. Peet, J. Y. Kim, N. E. Coates, W. L. Ma, D. Moses, A. J. Heeger, G. C. Bazan, Nat. Mater 2007, 6, 497; b) W. Ma, C. Yang, X. Gong, K. Lee, A. J. Heeger, Adv. Funct. Mater. 2005 , 15,1617 ; c) S. E. Shaheen, C. J. Brabec, N S. Sariciftci, F. Padinger, T. Fromherz, J. C. Hummelen, Appl. Phys. Lett. 2001, 78, 841.

[6] a) Y. Huang, E. J. Kramer, A. J. Heeger, G. C. Bazan, Chem. Rev. 2014, 114, 7006; b) F. Liu, Y. Gu, X. Shen, S. Ferdous, H.-W. Wang, T. P. Russell, Prog. Polym. Sci. 2013, 38, 1990.

[7] P. Westacott, J. R. Tumbleston, S. Shoaee, S. Fearn, J. H. Bannock, J. B. Gilchrist, S. Heutz, M. J. de, M. Heeney, H. Ade, J. Durrant, D. S. McPhail, N. Stingelin, Energy Environ. Sci. 2013, 6,2756

[8] a) J. A. Bartelt, Z. M. Beiley, E. T. Hoke, W. R. Mateker, J. D. Douglas, B. A. Collins, J. R. Tumbleston, K. R. Graham, A. Amassian, H. Ade, J. M. J. Fréchet, M. F. Toney, M. D. McGehee, Adv. Energy Mater. 2013, 3, 364; b) F. C. Jamieson, E. B. Domingo, T. McCarthyWard, M. Heeney, N. Stingelin, J. R. Durrant, Chem. Sci. 2012, 3, 485; c) B. A. Collins, J. R. Tumbleston, H. Ade, J. Phys. Chem. Lett. 2011, 2, 3135; d) A. C. Mayer, M. F. Toney, S. R. Scully, J. Rivnay, C. J. Brabec, M. Scharber, M. Koppe, M. Heeney, I. McCulloch, M. D. McGehee, Adv. Funct. Mater. 2009, 19, 1173.

[9] E. Buchaca-Domingo, A. J. Ferguson, F. C Jamieson, T. McCarthy-Ward, S. Shoaee, J. R. Tumbleston, O. G. Reid, L. Yu, M. B. Madec, M. Pfannmoller, F. Hermerschmidt, R. R. Schröder, S. E. Watkins, N. Kopidakis, G. Portale, A. Amassian, M. Heeney, H. Ade, G. Rumbles, J. R. Durrant, N. Stingelin, Mater. Horiz. 2014, 1, 270.

[10] a) B. H. Hamadani, D. J. Gundlach, I. McCulloch, M. Heeney, Appl. Phys. Lett. 2007 91, 243512; b) I. Mcculloch, M. Heeney, C. Bailey, K. Genevicius, M. I, M. Shkunov, D. Sparrowe, S. Tierney, R. Wagner, W. M. Zhang, M. L. Chabinyc, R. J. Kline, M. D. Mcgehee, M. F. Toney, Nat. Mater. 2006, 5, 328.

[11] M. Scarongella, J. De Jonghe-Risse, E. Buchaca-Domingo, M. Causa', Z. Fei, M. Heeney, J.-E. Moser, N. Stingelin, N. Banerji, J. Am. Chem. Soc. 2015, 137, 2908.
[12] W. L. Rance, A. J. Ferguson, T. McCarthyWard, M. Heeney, D. S. Ginley, D. C. Olson, G. Rumbles, N. Kopidakis, ACS Nano 2011, 5, 5635.

[13] N. C. Miller, E. Cho, M. J. Junk, R. Gysel, C. Risko, D. Kim, S. Sweetnam, C. E. Miller, L. J. Richter, R. J. Kline, M. Heeney, I. McCulloch, A. Amassian, D. Acevedo-Feliz, C. Knox, M. R. Hansen, D. Dudenko, B. F. Chmelka, M. F. Toney, J. L. Bredas, M. D. McGehee, $A d v$. Mater. 2012, 24, 6071.

[14] S. Sweetnam, K. R. Graham, G. O. Ngongang Ndjawa, T. Heumuller, J. A. Bartelt, T. M. Burke, W. Li, W. You, A. Amassian, M. D. McGehee, J. Am. Chem. Soc. 2014, 136, 14078.

[15] a) A. Zusan, K. Vandewal, B. Allendorf, N. H. Hansen, J. Pflaum, A. Salleo, V. Dyakonov, C. Deibel, Adv. Energy Mater. 2014, 4, 1400922 ; b) E. Buchaca-Domingo, K. Vandewal, Z. Fei, S. E. Watkins, F. H. Scholes, J. H. Bannock, J. C. de Mello, L. J. Richter, D. M. DeLongchamp, A. Amassian, M. Heeney, A. Salleo, N. Stingelin, J. Am. Chem. Soc. 2015, 137, 5256.

[16] A. A. Y. Guilbert, M. Schmidt, A. Bruno, J. Yao, S. King, S. M. Tuladhar, T. Kirchartz, M. I. Alonso, A. R. Goñi, N. Stingelin, S. A. Haque, M. Campoy-Quiles, J. Nelson, Adv. Funct. Mater. 2014, 6972.

[17] C. J. Brabec, G. Zerza, G. Cerullo, S. De Silvestri, S. Luzzati, J. C. Hummelen, S. Sariciftci, Chem. Phys. Lett. 2001, 340, 232.

[18] a) N. Banerji, J. Mater. Chem. C 2013, 1, 3052; b) K. Chen, A. J. Barker, M. E. Reish, K. C. Gordon, J. M. Hodgkiss, J. Am. Chem. Soc. 2013, 135, 18502.

[19] a) M. Causa', J. D. Jonghe-Risse, M. Scarongella, J. C. Brauer, E. BuchacaDomingo, J.-E. Moser, N. Stingelin, N. Banerji, Nature Commun., accepted; b) M. Scarongella, A. A. Paraecattil, E. Buchaca-Domingo, J. D. Douglas, S. Beaupré, T. McCarthy-Ward, M. Heeney, J.-E. Moser, M. Leclerc, J. M. J. Fréchet, N. Stingelin, N. Banerji, J. Mater. Chem. A 2014, 2, 6218; c) A. A. Paraecattil, N. Banerji, J. Am. Chem. Soc. 2014, 136, 1472.

[20] D. R. Kozub, K. Vakhshouri, S. V. Kesava, C. Wang, A. Hexemer, E. D. Gomez, Chem. Commun. 2012, 48, 5859 .

[21] a) F. Provencher, N. Berube, A. W. Parker, G. M. Greetham, M. Towrie, C. Hellmann, M. Cote, N. Stingelin, C. Silva, S. C. Hayes, Nat. Commun. 2014, 5, 4288; b) S. Gélinas, A. Rao, A. Kumar, S. L. Smith, A. W. Chin, J. Clark, T. S. van der Poll, G. C. Bazan, R. H. Friend, Science 2014, 343, 512; c) A. J. Barker, K. Chen, J. M.
Hodgkiss, J. Am. Chem. Soc. 2014, 136, 12018 ; d) D. Caruso, A. Troisi, Proc. Natl. Acad. Sci. USA 2012, 109, 13498; e) A. A. Bakulin, A. Rao, V. G. Pavelyev, P. H. M. van Loosdrecht, M. S. Pshenichnikov, D. Niedzialek, J. Cornil, D. Beljonne, R. H. Friend, Science 2012, 335 , 1340; f) I. A. Howard, R. Mauer, M. Meister, F. Laquai, J. Am. Chem. Soc. 2010, 132, 14866.

[22] a) T. M. Burke, M. D. McGehee, Adv. Mater 2014, 26, 1923; b) D. A. Vithanage, A. Devižis, V. Abramavicius, Y. Infahsaeng, D. Abramavicius, R. C. I. MacKenzie, P. E Keivanidis, A. Yartsev, D. Hertel, J. Nelson, V. Sundström, V. Gulbinas, Nat. Commun. 2013 , 4, 2334; c) K. Vandewal, S. Albrecht, E. T. Hoke, K. R. Graham, J. Widmer, J. D. Douglas, M. Schubert, W. R. Mateker, J. T. Bloking, G. F. Burkhard, A. Sellinger, J. M. J. Fréchet, A. Amassian, M. K. Riede, M. D. McGehee, D. Neher, A. Salleo, Nat. Mater. 2013, 13, 63.

[23] I.-W. Hwang, J. Y. Kim, S. Cho, J. Yuen, N. Coates, K. Lee, M. Heeney, I. McCulloch, D. Moses, A. J. Heeger, J. Phys. Chem. C 2008, $112,7853$.

[24] F. Dou, E. Buchaca-Domingo, M. Sakowicz, E Rezasoltani, T. McCarthy-Ward, M. Heeney, X. Zhang, N. Stingelin, C. Silva, J. Mater. Chem. C 2015, 3, 3722.

[25] a) M. Nyman, O. J. Sandberg, R. Österbacka, Adv. Energy Mater. 2015, 5, 1400890; b) D. W. Gehrig, I. A. Howard, S. Sweetnam, T. M. Burke, M. D. McGehee, F. Laquai, Macromol. Rapid Commun. 2015, 36, 1054.

[26] a) V. Pranculis, Y. Infahsaeng, Z. Tang, A. Devizis, D. A. Vithanage, C. S. Ponseca, Jr., O. Inganas, A. P. Yartsev, V. Gulbinas, V. Sundstrom, J. Am. Chem. Soc. 2014, 136 , 11331 ; b) P. M. Beaujuge, J. M. J. Fréchet, $J$ Am. Chem. Soc. 2011, 133, 20009.

[27] E. R. Bittner, C. Silva, Nat. Commun. 2014, 5 , 3119.

[28] M. Nyman, O. J. Sandberg, R. Österbacka, Synth. Met. 2015, 201, 6.

[29] a) B. Philippa, M. Stolterfoht, P. L. Burn, G. Juska, P. Meredith, R. D. White, A. Pivrikas, Sci. Rep. 2014, 4, 5695; b) A. Melianas, V. Pranculis, A. Devižis, V. Gulbinas, O. Inganäs, M. Kemerink, Adv. Funct. Mater. 2014, 24. 4507; c) R. Noriega, J. Rivnay, K. Vandewal, F. P. V. Koch, N. Stingelin, P. Smith, M. F. Toney, A. Salleo, Nat. Mater. 2013, 12, 1038. 